\title{
Room Temperature Regulation System Based on Air and Water Heat Exchange
}

\author{
Quan Wang ${ }^{1}$ a $^{*}$, Lingsong Ding ${ }^{1}$ and Ce Wang ${ }^{1}$ \\ ${ }^{1}$ North China Electric Power University, Beijing, 102206 \\ aalanncepu@foxmail.com
}

Keywords: Reuse of floor heating pipe; Convective heat transfer; The room temperature control system; Indoor air circulation; Auto-Control

\begin{abstract}
The project based on the innovation and reuse of the floor heating pipe, designed a room temperature control system which can realize indoor air and floor heating pipe convective heat exchange. The system uses the three-dimensional space between the ground and the heating pipe, and is supplemented by a quiet air blower, which causes the indoor air to enter the underground space from the air inlet of the ground, and return to the room after the convection heat exchange, so as to achieve the effect of regulating the room temperature and promoting the indoor air circulation. In addition, the project can realize the automatic control of the indoor temperature with the temperature sensor and the related circuit. The project has a significant effect of energy saving and emission reduction, improving the comfort of people in the room, which can effectively assist the winter heating and reduce the use of the summer air conditioner.
\end{abstract}

\section{Introduction}

The design of the project is mainly based on two backgrounds. The first is that recently in our country the floor heating is growing popular and its proportion of household heating system is more and more big. However existing interior design but did not achieve fully use on the floor heating pipe, especially in summer floor heating pipe does not participate in any heat exchange, for temperature control in a state of zero contribution, so that floor heating pipe with good heat transfer performance didn't get effective play. The second is the amount of air conditioner in China increased year by year, as a kind of household electrical appliances to adjust room temperature, with a high frequency use, especially in summer. However, the use of air conditioning will produce a series of follow-up questions such as indoor air conditioning, outdoor air conditioning, noise pollution and air pollution. Therefore, it's a need for a new type of heat transfer system to replace temperature adjustment function of the air conditioning regulation at room temperature.

The development of this system is to solve the above two problems. It can directly use the hot water heating in winter, introduce the tap water from floor heating pipeline summer and warm in the, as to implement the annual heat exchange utilization. It can realize the indoor air and heating direct heat convection through the silent fan, increasing the heat transfer efficiency, both to assist the winter heating, but also to reduce the use of summer air conditioning, so as to play the effect of energy-saving emission reduction

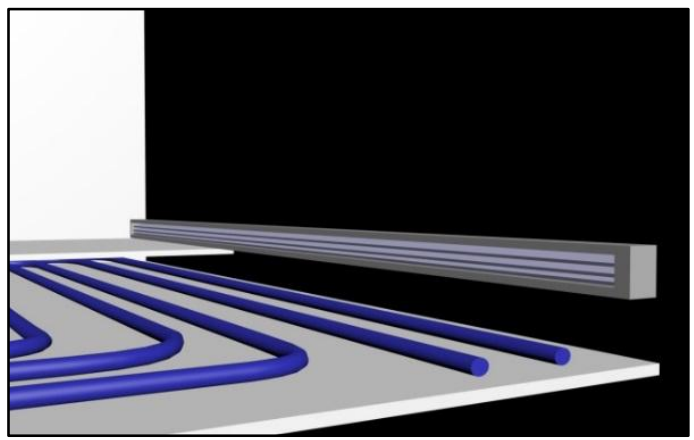

Figure 1. Schematic diagram of the three-dimensional space between the ground and the heating pipe 


\section{Basic Principle}

It used as refrigeration in summer and use fan to pump indoor air into the ground through the air inlet side of the lower (there is a three-dimensional space between the ground and the heating pipe, as shown in Fig. 1). Air inlet is provided with a wind distribution plate and makes the air into parallel wind sweeping across the pipe surface, after heat exchange with tap water in floor heating pipe, air conditioning is the lower temperature, into the other side of the gas collecting pipe, and finally from the height of the air outlet back to the room.

When it's in winter used for heating, Air is pumped into the ground by the air inlet by the air blower, after the cold air and hot water heat exchange, the hot air is discharged from the original air inlet which is supplementary to play a heating effect for floor heating. At the same time, the system also is added with the single-chip microcomputer, temperature sensor as the core of the automatic temperature control function, that system will change with the indoor temperature, automatically change the fan stall, and then change the effect of temperature control system. 2.

In the system, the indoor air circulation and the convective heat transfer process are shown in Fig.
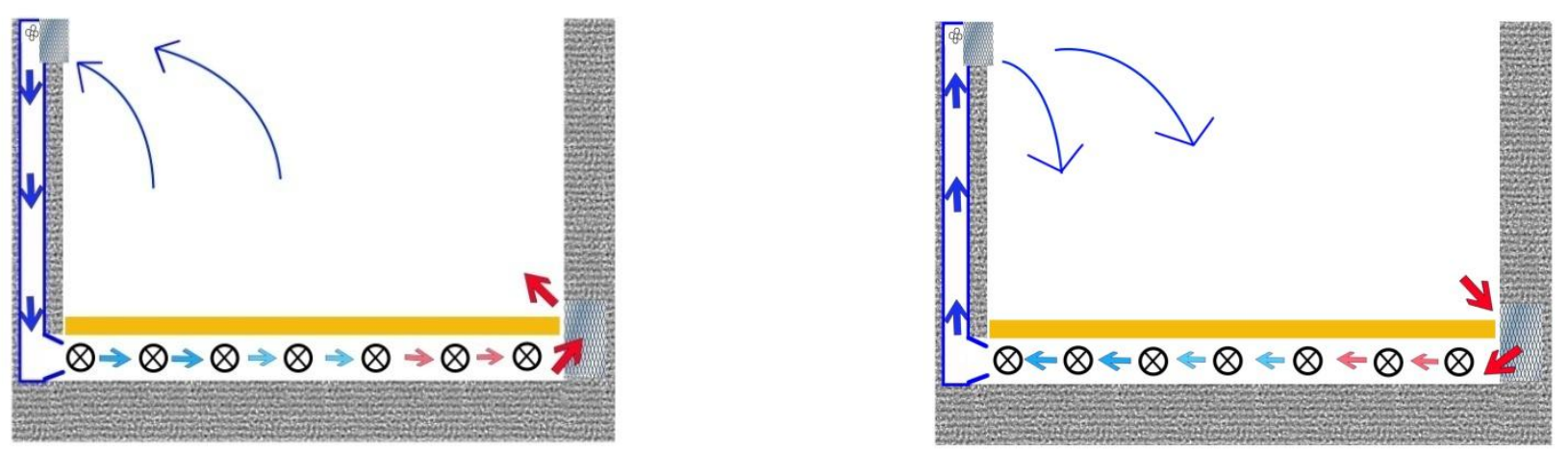

Figure 2. Schematic diagram of air circulation in winter and summer room temperature regulation system

\section{Modeling of the System and the CFD Simulation of Convective Heat Transfer}

This system requires simulation and calculation of the convection heat transfer situation on the air and floor heating pipe. While the parameter setting and the theoretical calculating, it is assumed that the indoor space is a space of 8 meters wide, 3 meters wide and 10 meters high. In order to facilitate the CFD simulation and simplifying calculation of the heat transfer process, it is assumed that the heating pipes are transversely arranged, and the airs cross flow. Piping material is made of heat resistant polyethylene pipe (PE-RT pipe).

Setting boundary conditions, fluent software is used to simulate the speed, through the analysis of the velocity field around the heating pipe, to get air in the average velocity in the process of heat exchange with the floor heating pipe is $1.5 \mathrm{~m} / \mathrm{s}$, the maximum speed of $2.97 \mathrm{~m} / \mathrm{s}$.

Summer heat transfer: the simulation conditions for the heat transfer before the indoor temperature of 28.5 degrees Celsius, the average velocity of air flow in the surface of the underground pipe is $1.5 \mathrm{~m} / \mathrm{s}$. Finally, the temperature distribution on the surface of the summer pipeline is shown in Fig. 3. By analyzing the around the floor heating pipe temperature field, the result is that air inlet temperature in the process of heat exchange with the floor heating pipe is 28.5 degrees Celsius, the outlet temperature for 25.8 degrees Celsius. 

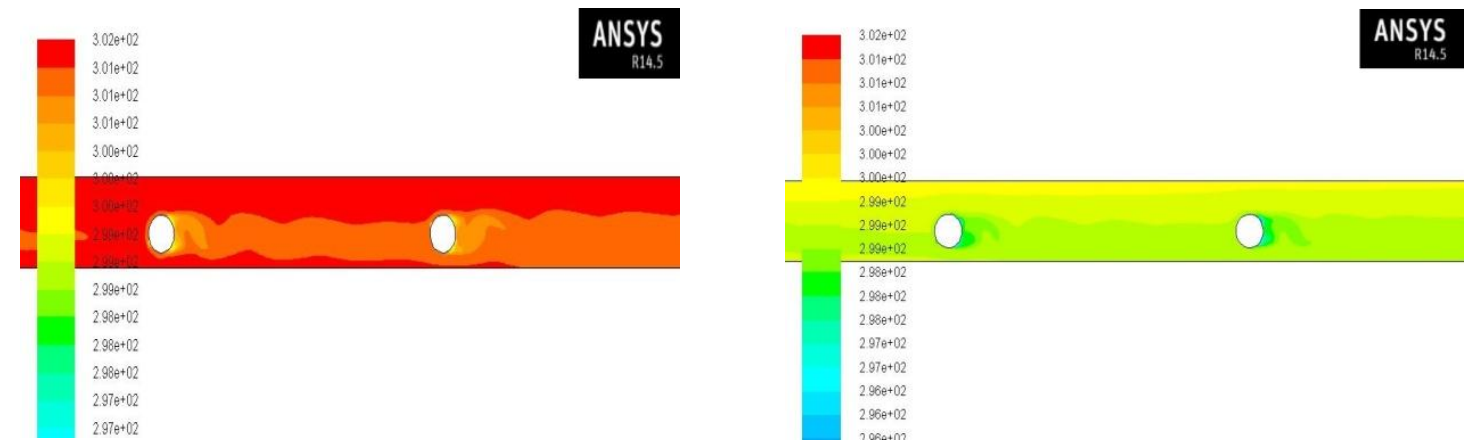

Figure 3. Temperature distribution at the inlet and outlet of summer heat exchange

Winter heat transfer: simulation conditions for the heat transfer before the indoor temperature of 18.5 degrees Celsius, the average velocity of air flow on the surface of the underground pipe is $1.5 \mathrm{~m} / \mathrm{s}$. Finally, the temperature distribution of the surface temperature distribution of the summer pipeline is shown in Fig. 4. By around the floor heating pipe temperature field analysis, air inlet temperature in the process of heat exchange with the floor heating pipe for 18.5 degrees Celsius, the outlet temperature is 22.8 degrees Celsius.

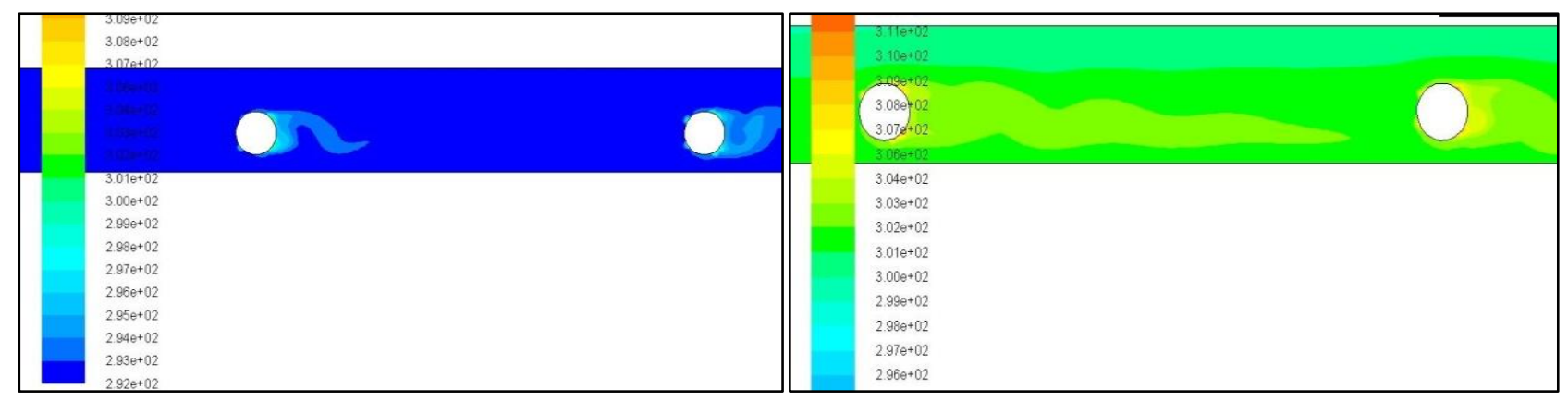

Figure 4. Temperature distribution of heat exchange inlet and outlet in winter

\section{System Performance Test}

3D Modeling and System Model Making. This work uses the 3DMAX software to carry on the modeling; the model is shown in Fig. 5.

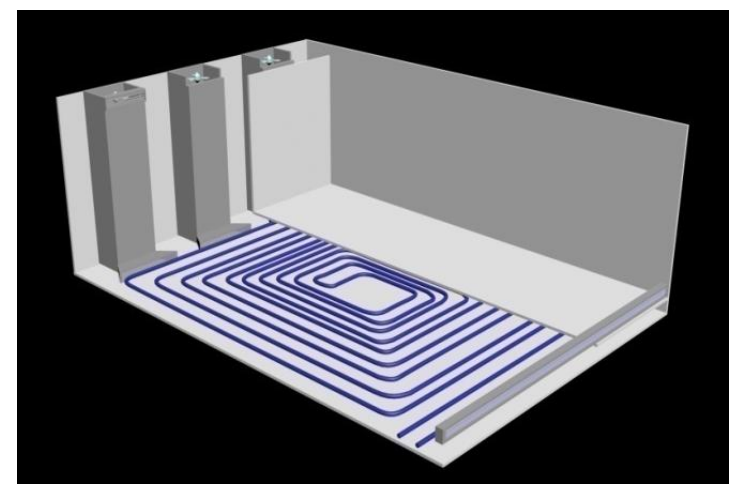

Figure 5. 3D model of room temperature control system 


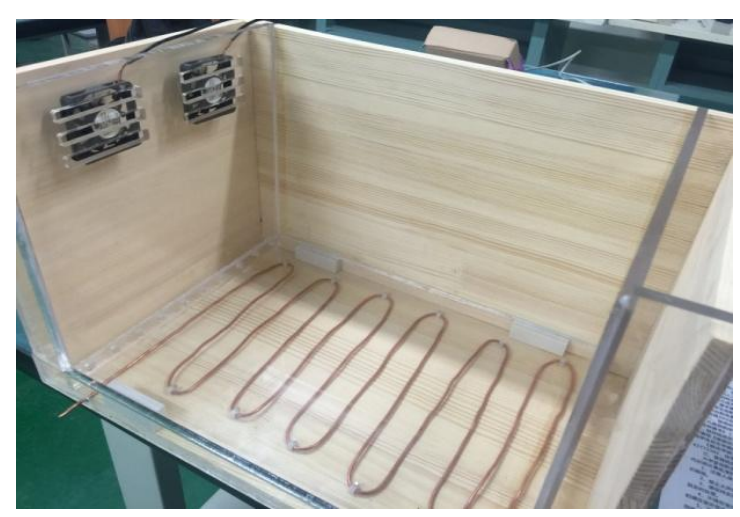

Figure 6. The overall effect of the model

In the actual production of the system model, use wood and acrylic plate to constitute the basic framework of the model room, brass simulation actual floor heating pipe in underground distribution, as shown in Fig. 6 The square shaped structure is actually a grid type inlet and outlet air outlet, and the bottom of the long row of holes is arranged on the ground.

System Performance Test Trial. Use the physical model of the system to simulate the actual operating conditions. Simulated operating conditions are for the summer indoor air temperature of 28.5 degrees Celsius, the pipe water temperature of 13.5 degrees Celsius, the winter indoor temperature of 18.5 degrees Celsius, and the water temperature of 56 degrees Celsius. Temperature measurement uses a thermal resistance thermometer.

By two fans promote air circulation air and heating pipe heat exchanger, every 15 minutes record heat outlet air temperature and average indoor temperature an underground heat exchanger. The simulation of a total of 5 experiments, the average value obtained after the experimental data as shown in table 1 .

Table 1 Experimental data record

\begin{tabular}{|c|c|c|c|c|c|c|}
\hline \multirow{2}{*}{$\begin{array}{c}\text { time } \\
\text { (min) }\end{array}$} & \multicolumn{2}{|c|}{ Summer } & (unit: degrees Celsius) & \multicolumn{3}{|c|}{ winter (unit: degrees Ce1sius) } \\
\cline { 2 - 7 } & $\begin{array}{c}\text { Inlet } \\
\text { temperature }\end{array}$ & $\begin{array}{c}\text { Outlet } \\
\text { temperature }\end{array}$ & $\begin{array}{c}\text { indoor } \\
\text { temperature }\end{array}$ & $\begin{array}{c}\text { Inlet } \\
\text { temperature }\end{array}$ & $\begin{array}{c}\text { Outlet } \\
\text { temperature }\end{array}$ & $\begin{array}{c}\text { indoor } \\
\text { temperature }\end{array}$ \\
\hline 0 & 28.5 & 28.5 & 28.5 & 18.5 & 18.5 & 18.5 \\
\hline 15 & 28.1 & 26.5 & 28.1 & 19.2 & 23.8 & 19.2 \\
\hline 30 & 27.4 & 26.2 & 27.4 & 19.6 & 24.2 & 19.6 \\
\hline 45 & 27.1 & 25.6 & 27.1 & 20.2 & 24.7 & 20.2 \\
\hline 60 & 26.7 & 24.9 & 26.7 & 20.9 & 25.3 & 20.9 \\
\hline 70 & 26.3 & 23.5 & 26.3 & 21.3 & 25.8 & 21.3 \\
\hline 80 & 25.9 & 22.3 & 25.9 & 21.7 & 26.2 & 21.7 \\
\hline 90 & 25.5 & 20.5 & 25.5 & 22.4 & 26.6 & 22.4 \\
\hline 100 & 25.3 & 19.2 & 25.3 & 22.7 & 27.0 & 22.7 \\
\hline
\end{tabular}

Analysis of the experimental data can be drawn, the average heat transfer coefficient of this experiment is about $19.87 \mathrm{~W} /(\mathrm{m} 2 / \mathrm{K})$, and there is a certain deviation from the theoretical value. Taking into account that the air flow control is not accurate and temperature measurement imprecision, experiment device hermeticity difference there is leakage phenomenon, the room model factors such as heat preservation measures are not taken, the system still has a great potential for energy saving.

\section{Comprehensive Analysis of Test Results}

The system through the silent fan makes the indoor air and heating direct heat convection, with a high Heat transfer efficiency, which can assist the winter heating to reduce the temperature of the 
hot water, and can reduce the use of the summer air conditioner, thereby saving energy and reducing the effect of the energy saving and emission reduction. To the room with 80 square meters as an example, in the summer it can save $1.2 \mathrm{kWh}$ of electricity per hour (assuming that the cooling power per square meter is $160 \mathrm{~W}$, the energy consumption of air conditioning is 3.6 , and the total power of the silent air blower is $120 \mathrm{~W}$, the average working time is 6 hours per day). Winter auxiliary heating warm per hour reduction in heat supply of about $26480 \mathrm{KJ}$, if use of coal-fired heating, a hour can reduce $1.18 \mathrm{Kg}$ coal consumption reduce $2.38 \mathrm{Kg}$ emissions of carbon dioxide (assuming the flow of a heating pipeline for $0.8 \mathrm{~m} 3 / \mathrm{h}$, coal of the exothermic quantity for $22415 \mathrm{KJ} / \mathrm{Kg}$, containing carbon content is $65 \%$ ).

This shows that the heat transfer effect of the system is obvious, the energy saving potential is huge. Because the system is designed based on the existing floor heating pipe, applicability strong, coupled to warm heating development momentum better, and therefore the application prospect of this project is very wide.

\section{References}

[1] Compilation of the National Bureau of statistics of the people's Republic of china, "China Statistical Yearbook - 2015", China Statistics Press, 2015.09

[2] Li Jiangnan "Problems" should pay attention to the design and construction of a [J]"Construction supervision" -2011 08 periods

[3] Li Zhao jian, Jiang Yi, "China's urban residential summer air conditioning energy consumption status analysis" [J]" Heating Ventilating and Air Conditioning"-05 phase of -2009

[4] Duan Zhong zhe, editor in chief, "analysis of FLUENT ANSYS fluid and engineering example", publishing house of electronics industry, 2014.06

[5] Edited by Tao Wenquan, Yang Shiming, "heat transfer" fourth edition, higher education press, 2014.12

[6] Chen Qun, Wu Jing, Ren Jianxun "Thermodynamic optimization and heat transfer optimization of convective heat transfer process" [J]"Journal of engineering thermal physics", the 02 phase of -2008

[7] Zhong Liying" anaylysis On the "China floor heating industry [J]"Beijing agriculture" 12 period -2011

[8] Liu Sheng chun, Ma Yitai, Lu Wwei" Air conditioning energy efficiency ratio and seasonal energy efficiency ratio analysis" [J] "Journal of Tianjin University" -2006 09 period

[9] Jin Ling, Liu Yanhua, "the application of CFD in the greenhouse indoor environment research" [J] "Anhui Agricultural Sciences" -2012 07 period

[10] Fu Yun "Research on temperature stability in the temperature test" [J] "environmental art" -200103 period 